\title{
Design and Implementation of Astable Multivibrator using 555
} Timer

\author{
Md. Moyeed Abrar \\ Department of Computer Science \&Engineering, Khaja Banda Nawaz College of Engineering, Kalaburagi, \\ Karnataka, India
}

\begin{abstract}
The 555 timer is widely used as IC timer circuit and it is the most commonly used general purpose linear integrated circuit. It can run in either one of the two modes: Monostable (one stable state) or Astable (no stable state). In the Monostable mode it can produce accurate time delays from microseconds to hours. In the Astable mode it can produce rectangular waveforms with a variable Duty cycle. The simplicity and ease with which both the multivibrator circuits can be configured around this IC is one of the main reasons for its wide use. The state of the art presented in the paper is the design and implementation of an Astable multivibrator using 555 timer IC, generating non-sinusoidal waveform in the form of Rectangular waveform as well as capacitor voltage waveform in the form of ramp waveform.
\end{abstract}

Keywords: Astable multivibrator, Duty cycle, Ramp waveform, Rectangular waveform, 555 timer.

\section{Introduction}

Oscillators are broadly classified into two categories namely sinusoidal and non-sinusoidal oscillators. Sinusoidal oscillators produce a sine wave output and the non-sinusoidal oscillators produce a square or pulsed output. A multivibrator circuit is basically a non-sinusoidal oscillator with a regenerative feedback. A multivibrator circuit is a two state circuit that has zero, one or two stable output states. Depending on the number of stable output states there are three basic types of multivibrator circuits namely Bistable multivibrator having two stable states, Monostable multivibrator having one stable state and Astable multivibrator having zero stable states. [1] In the case of Monostable and Bistable multivibrator an external trigger pulse is required for their operation whereas in the case of Astable multivibrator it has automatic built in triggering which switches it continuously between its two unstable states both SET and RESET. There are two main components in every multivibrator namely the bistable circuit and the two passive networks that are connected in a basic feedback loop. The networks in the circuit can be Monostable (resistive), Astable (resistive-capacitive) or bistable. Astable multivibrator is built of two amplifying stages that are connected in a positive feedback loop using two resistive-capacitive coupling networks. The elements used for amplification may be junction field effect transistors, bipolar junction transistors, vacuum tubes, operational amplifiers or any other type of amplifier. They are essentially used in wide variety of systems where a timed interval or a square wave is required [1], [2].

The 555 timer can be connected to run as an Astable multivibrator. When used in this way, the 555 timer has no stable states, which implies that it cannot remain indefinitely in either state. Stated in another way, it oscillates when operated in the Astable mode and produces a Square or Rectangular output signal.

The rest of the paper is organized into sections as follows: section II describes the overview of the Astable multivibrator using timer IC 555. Section III focuses on the system design. Experimental results and discussions are reported in Section IV. Finally section V summarizes the paper and presents the concluding remark.

\section{Astable Multivibrator Using Timer IC 555 Overview}

The basic 555 timer based Astable multivibrator circuit is depicted in fig 1. Initially, capacitor $\mathrm{C}$ is fully discharged, which forces the output to go to the HIGH state. An open discharge transistor allows capacitor $C$ to charge from $+V_{c c}$ through resistors $R_{1}$ and $R_{2}$. When the voltage across $C$ exceeds $+2 V_{c c} / 3$, the output enters the LOW state and the discharge transistor is switched $\mathrm{ON}$ at the same time. Capacitor $\mathrm{C}$ starts to discharge through $R_{2}$ and the discharge transistor inside the IC. When the voltage across $C$ falls below $+V_{c c} / 3$, the output enters the HIGH state. The charge and discharge cycles repeat and the circuit behaves as a free running multivibrator. Terminal- 4 of the IC is the RESET terminal. Usually, it is connected to $+\mathrm{V}_{\text {cc. }}$ If the voltage at this terminal is driven below 0.4 , the output is forced to the LOW state overriding command pulses at terminal-2 of the IC. HIGH state and LOW state time periods are governed by the charge $\left(+\mathrm{V}_{\mathrm{cc}} / 3\right.$ to $\left.+2 \mathrm{~V}_{\mathrm{cc}} / 3\right)$ and discharge $\left(+2 \mathrm{~V}_{\mathrm{cc}} / 3\right.$ to $\left.+\mathrm{V}_{\mathrm{cc}} / 3\right)$ timings. These are given by (1) and (2) respectively.

HIGH state time period, $\mathrm{T}_{\mathrm{HIGH}}=0.69 \times\left(\mathrm{R}_{1}+\mathrm{R}_{2}\right) \times \mathrm{C}$

LOW state time period, $\mathrm{T}_{\mathrm{LOW}}=0.69 \times \mathrm{R}_{2} \times \mathrm{C}$ 


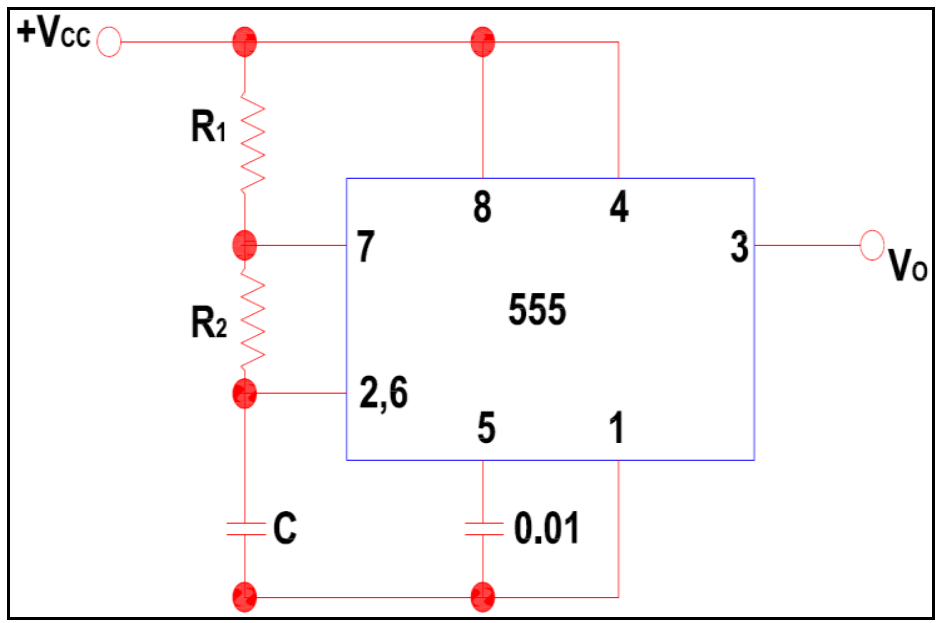

Fig. 1 Astable multivibrator circuit using 555 timer.

The HIGH state time period is also known as Turn ON time $\left(\mathrm{T}_{\mathrm{ON}}\right)$ and the LOW state time period is also known as Turn OFF time $\left(\mathrm{T}_{\mathrm{OFF}}\right)$. The relevant waveforms are shown in fig 2.

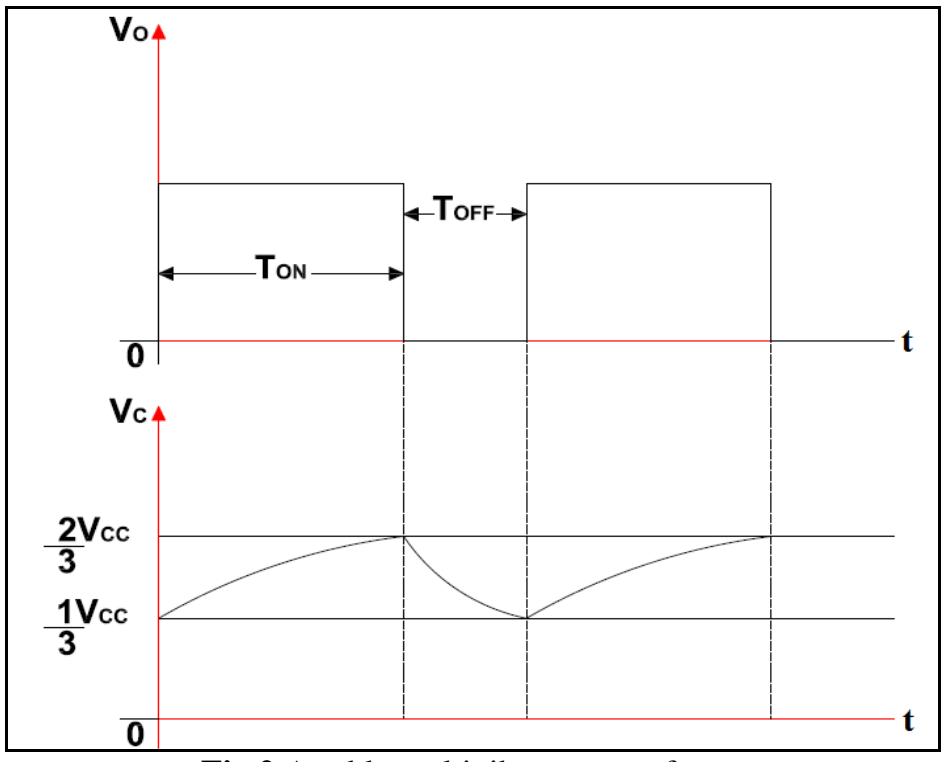

Fig.2 Astable multivibrator waveforms

The time period (T) and frequency (f) of the output waveforms are given by (3) and (4) respectively.

Time period, $\mathrm{T}=0.69 \times\left(\mathrm{R}_{1}+2 \mathrm{R}_{2}\right) \times \mathrm{C}$

Frequency $f=1 / 0.69 \times\left(R_{1}+2 R_{2}\right) \times C$

\subsection{Hardware Design.}

\section{System Design}

Given frequency $=1 \mathrm{KHz}$ and duty cycle $=60 \%(0.6)$

Time period $\mathrm{T}=1 / \mathrm{f}=\mathrm{T}_{\mathrm{ON}}+\mathrm{T}_{\mathrm{OFF}}=1 \mathrm{msec}$

Where $\mathrm{T}_{\mathrm{ON}}$ is the time the output is high and $\mathrm{T}_{\mathrm{OFF}}$ is the time the output is low.

From the concept of Astable Multivibrator using 555 timer we have

$\mathrm{T}_{\mathrm{HIGH}}=\mathrm{T}_{\mathrm{ON}}=0.693 \mathrm{R}_{\mathrm{B}} \mathrm{C}$

$\mathrm{T}_{\mathrm{LOW}}=\mathrm{T}_{\mathrm{OFF}}=0.693\left(\mathrm{R}_{\mathrm{A}}+\mathrm{R}_{\mathrm{B}}\right) \mathrm{C}$

$\mathrm{T}=\mathrm{T}_{\mathrm{ON}}+\mathrm{T}_{\mathrm{OFF}}$

$\mathrm{T}=0.693 \mathrm{R}_{\mathrm{B}} \mathrm{C}+0.693\left(\mathrm{R}_{\mathrm{A}}+\mathrm{R}_{\mathrm{B}}\right) \mathrm{C}$

$\mathrm{T}=0.693\left(\mathrm{R}_{\mathrm{A}}+2 \mathrm{R}_{\mathrm{B}}\right) \mathrm{C}$

Duty cycle $\mathrm{D}=\left[\mathrm{T}_{\mathrm{ON}} /\left(\mathrm{T}_{\mathrm{ON}}+\mathrm{T}_{\mathrm{OFF}}\right)\right]$

$\mathrm{D}=\left[\mathrm{T}_{\mathrm{ON}} / \mathrm{T}\right]$ 
$0.6=\mathrm{T}_{\mathrm{ON}} / \mathrm{T}$

$\mathrm{T}_{\mathrm{ON}}=0.6 \mathrm{~T}=0.6 \mathrm{msec}$

From (8), $\mathrm{T}_{\mathrm{OFF}}=\mathrm{T}-\mathrm{T}_{\mathrm{ON}}$

$\mathrm{T}_{\mathrm{OFF}}=1 \mathrm{msec}-0.6 \mathrm{msec}=0.4 \mathrm{msec}$

Let $\mathrm{C}=0.1 \mu \mathrm{f}$ and substituting in (6) and (7) we get

$\mathrm{R}_{\mathrm{B}}=5.8 \mathrm{~K} \Omega$ and $\mathrm{R}_{\mathrm{A}}=2.9 \mathrm{~K} \Omega$

Duty cycle determined by $\mathrm{R}_{\mathrm{A}}$ and $\mathrm{R}_{\mathrm{B}}$ can vary only between $50 \%$ and $100 \%$

When frequency $=1 \mathrm{KHz}$ and duty cycle $=75 \%, \mathrm{R}_{\mathrm{A}}=7.2 \mathrm{~K} \Omega$ and $\mathrm{R}_{\mathrm{B}}=3.6 \mathrm{~K} \Omega$

For the circuit design, choosing $\mathrm{R}_{\mathrm{A}}=6.8 \mathrm{~K} \Omega$ and $\mathrm{R}_{\mathrm{B}}=3.3 \mathrm{~K} \Omega$.

The circuit schematic for the Astable multivibrator using 555 timer is depicted in fig 3.

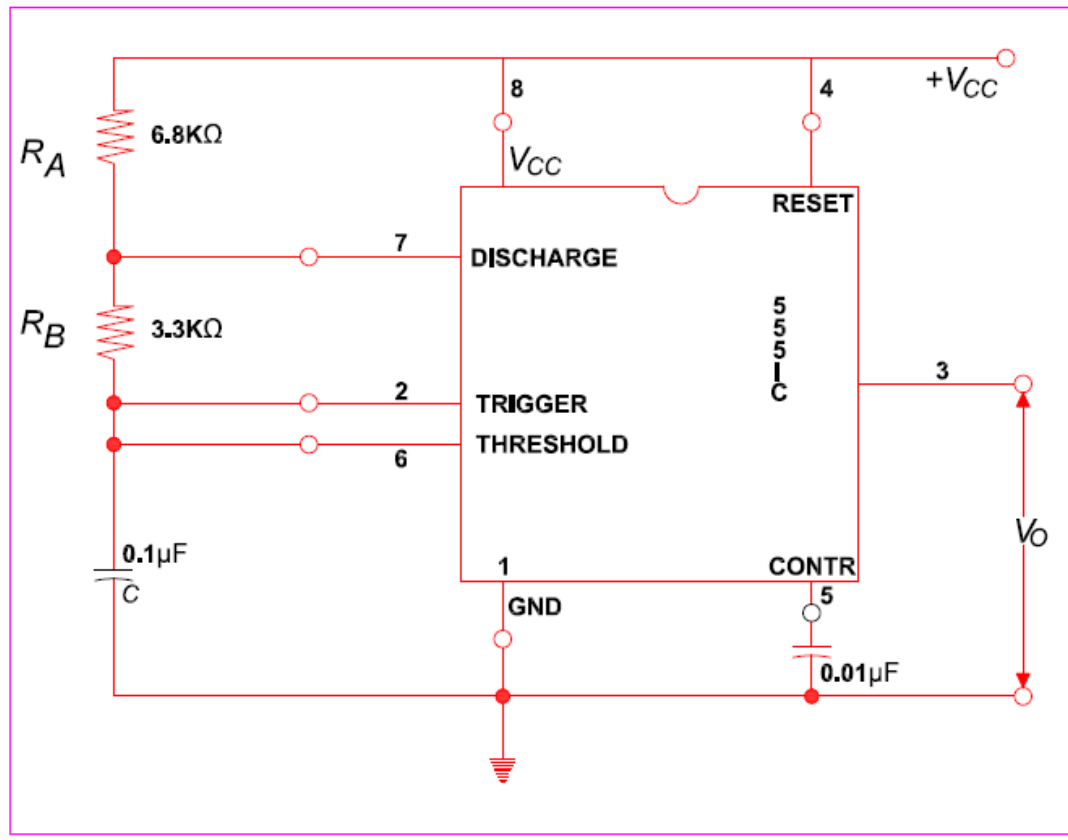

Fig. 3 Astable multivibrator circuit schematic

\subsection{System specifications}

The system specifications are illustrated in TABLE 1

TABLE 1. System Specifications

\begin{tabular}{|c|c|}
\hline Sl. No & Specifications \\
\hline 1. & Domain: Analog electronics, Electronic circuits. \\
\hline 2. & Timer IC: LM 555 \\
\hline 3. & Resistors: $3.3 \mathrm{~K} \Omega, 6.8 \mathrm{~K} \Omega$ \\
\hline 4. & Capacitors : $0.1 \mu \mathrm{F}, 0.01 \mu \mathrm{F}$ \\
\hline 5. & Digital trainer IC kit \\
\hline 6. & Breadboard \\
\hline 7. & DC regulated power supply: $+5 \mathrm{~V}$ \\
\hline 8. & Multimeter \\
\hline 9. & $\begin{array}{l}\text { Connecting probes, Single stranded connecting wires, } \\
\text { patch cords, crocodile clips. }\end{array}$ \\
\hline 10. & Cathode ray Oscilloscope (CRO) \\
\hline 11. & $\begin{array}{l}\text { Applications: Non-sinusoidal waveform generation } \\
\text { such as Rectangular, square and ramp waveform etc. }\end{array}$ \\
\hline 12. & Simulation Software: Multisim 12. \\
\hline
\end{tabular}

\subsection{Timer I.C 555 overview}

The 555 monolithic timing IC is a highly stable controller capable of generating accurate time delays, or oscillation. In the time delay mode of operation, the time is precisely controlled by one external resistor and capacitor. For a stable operation as an oscillator, the free running frequency and the duty cycle are both accurately controlled with two external resistors and one capacitor. The circuit may be triggered and reset on falling waveforms, and the output structure can source or sink upto 200mA. [7], [8], [12]. 
The sailent features of this IC are

i) Can be operated in both Astable and Monostable modes.

ii) Maximum operating frequency greater than $500 \mathrm{KHz}$.

iii) Has Turn-OFF time less than $2 \mu \mathrm{s}$.

iv) High output current

v) Adjustable duty cycle

vi) TTL compatible.

Fig. 4 shows the pin diagram of 555 timer. It is an 8 pin IC packed in dual in line package. Different pins of the 555 timer are designated as Ground (pin no.1), Trigger (pin no.2), Output (pin no.3), Reset (pin no.4), Control (pin no.5), Threshold (pin no.6), Discharge (pin no.7) and $+\mathrm{V}_{\mathrm{CC}}$ (pin no.8).

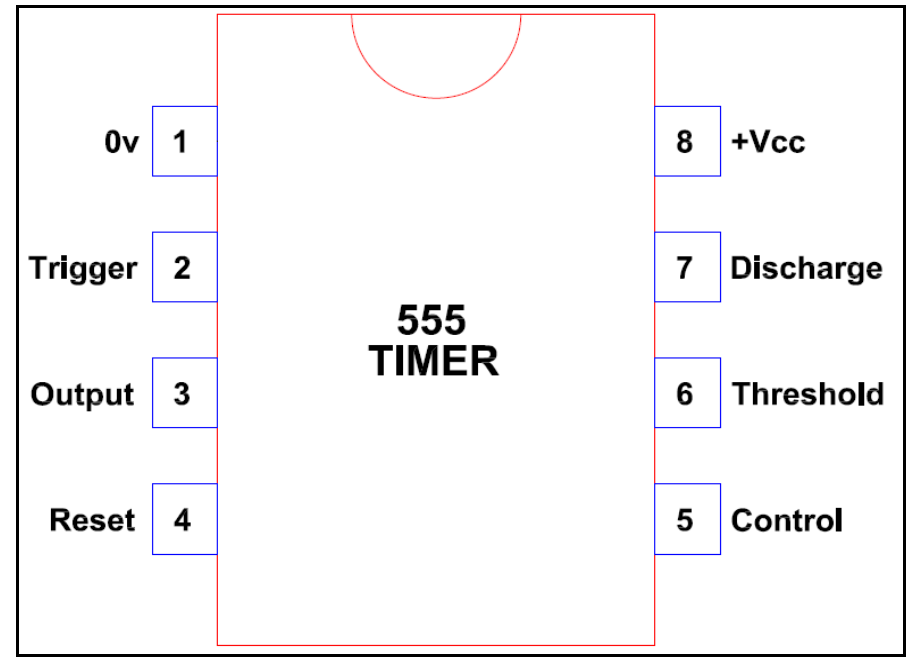

Fig. 4 Timer I.C 555 pin diagram

Fig. 5 shows the internal schematic of timer IC 555. It comprises of two opamp comparators, a SR flip flop, a discharge transistor, a reset transistor, three identical resistors and an output stage. The resistors set the reference voltage levels at the non inverting input of the lower comparator and inverting inputs of the upper comparator at $+\mathrm{V}_{\mathrm{cc}} / 3$ and $+2 \mathrm{~V}_{\mathrm{cc}} / 3$, respectively. Outputs of the two comparators feed SET and RESET inputs of the SR flip flop and thus decide the logic status of its output and subsequently the final output. The flip flops complementary outputs feed the base of the discharge transistor and the output stage. This ensures that when the output is HIGH, the discharge transistor is OFF and when the output is LOW, the discharge transistor is ON. [1], $[2]$.

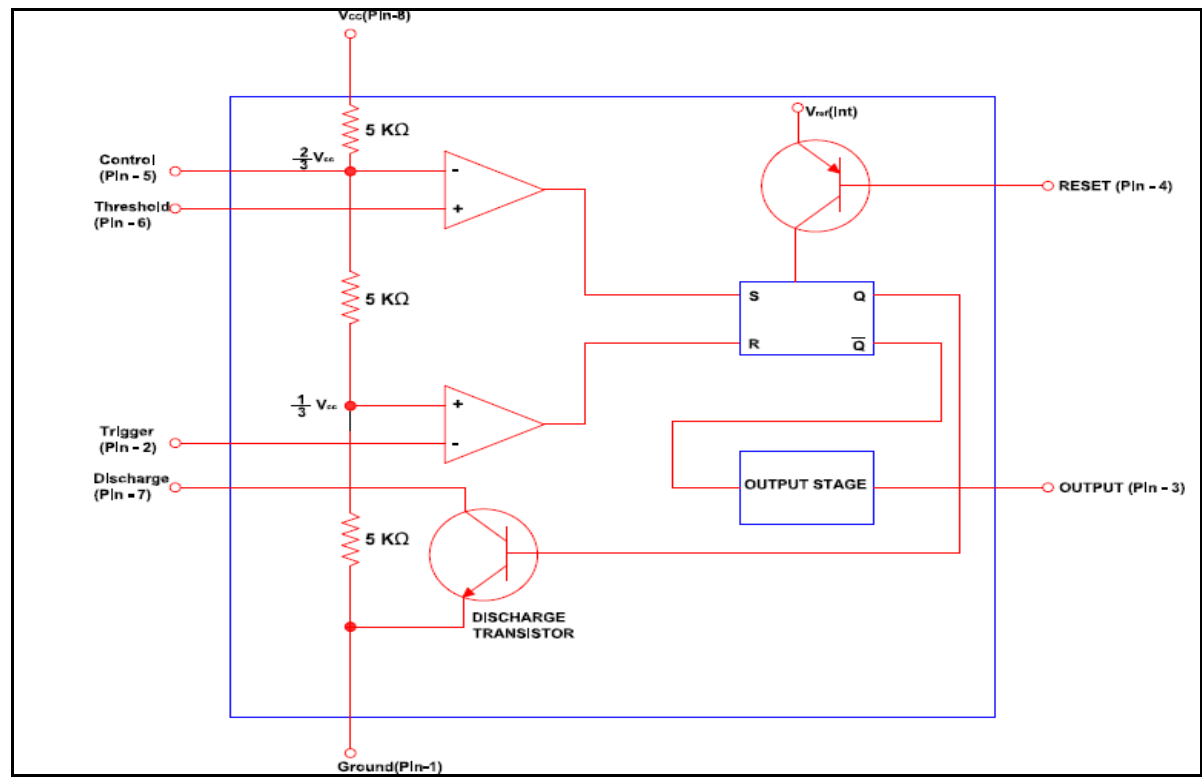

Fig. 5 Internal schematic of 555 timer 


\subsection{System set up}

The experimental set up was done in Analog and Digital electronics laboratory. According to the hardware design the required components were taken and the resistor values were checked using a Multimeter. The system was rigged as per the circuit schematic on a breadboard and the supply voltage to the IC was provided through the digital trainer kit. The power supply was switched ON to get the output waveform in the form of Rectangular waveform and then to get capacitor voltage waveform in the form of Ramp waveform. The rigged up circuit for the former and latter cases are depicted in fig. 6 and 7 respectively.

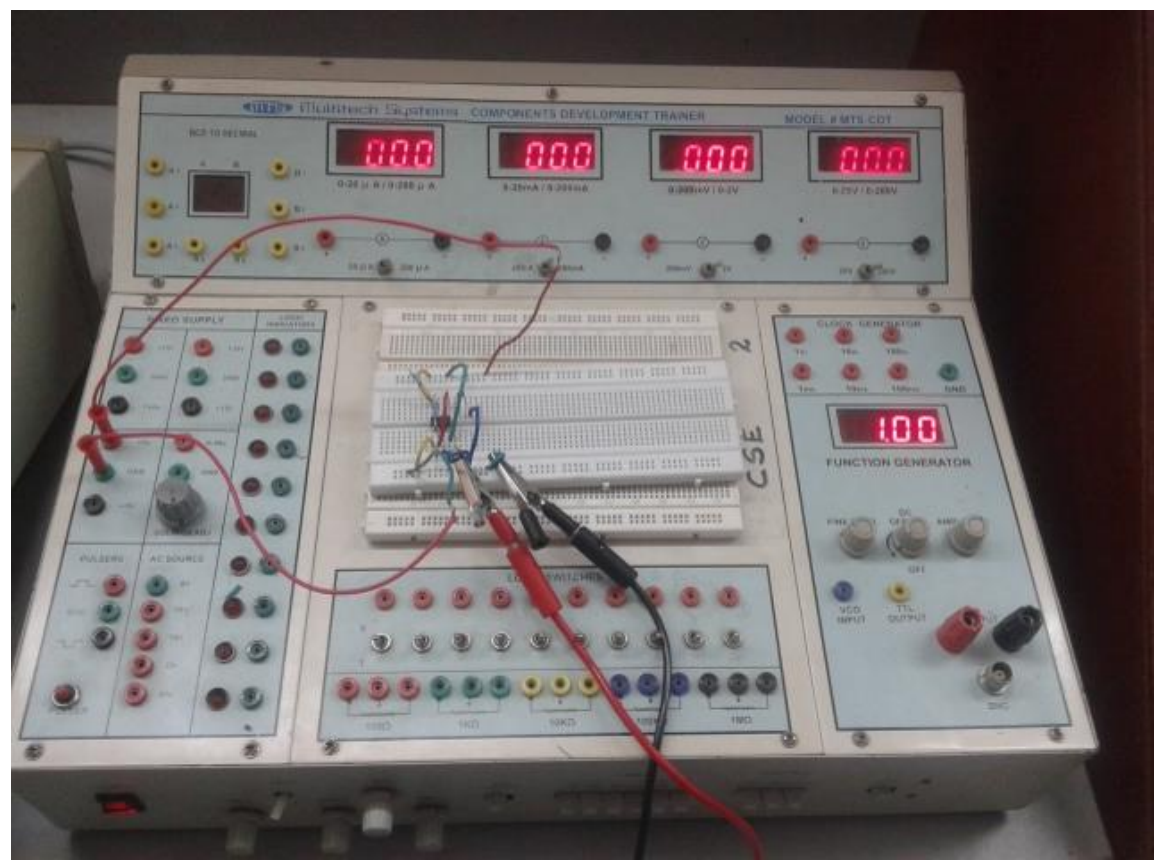

Fig. 6 Photographic view of the system to generate Rectangular waveform

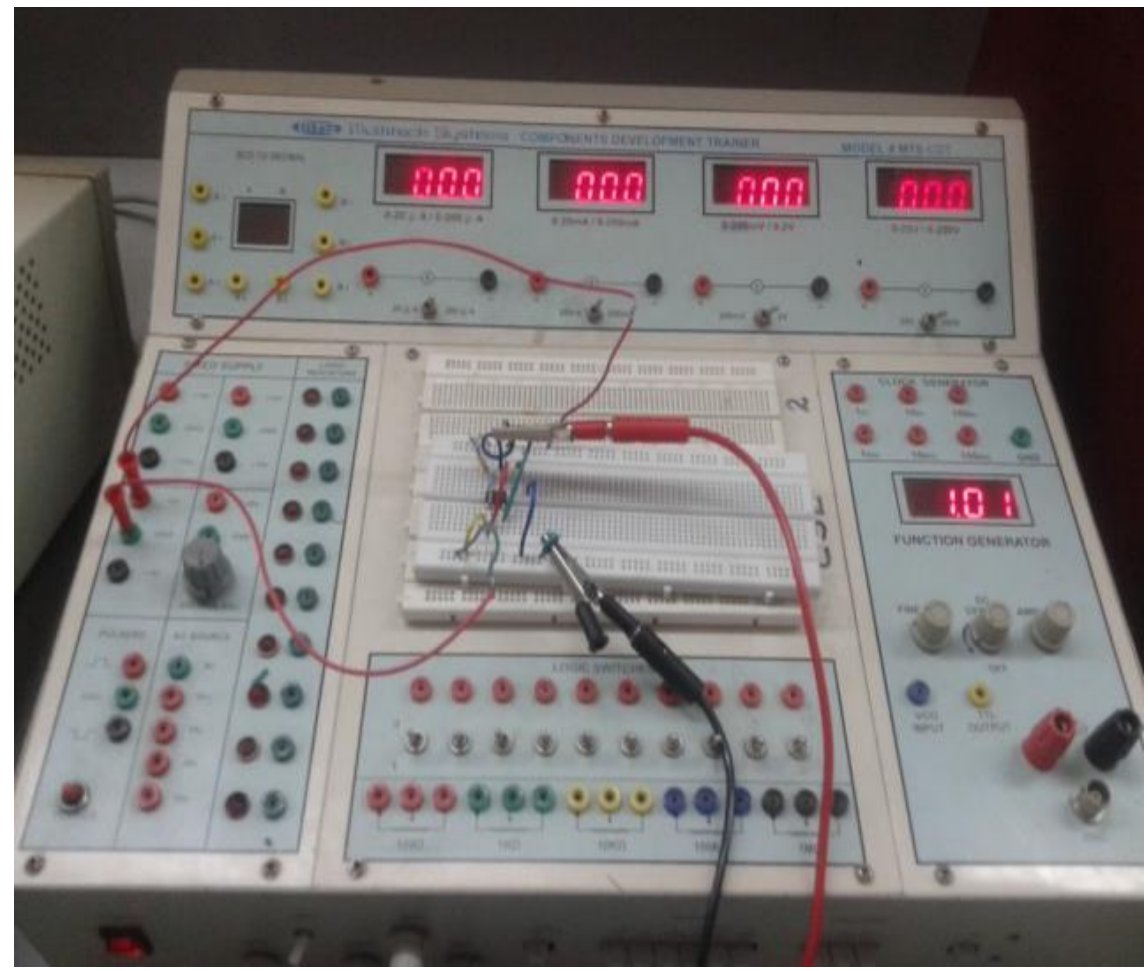

Fig. 7 Photographic view of the system to generate Ramp waveform 


\subsection{Hardware Results}

\section{Results And Discussions}

The output waveform in the form of a Rectangular wave was observed on the CRO when the positive probe from channel 2 was connected at pin number 3 of the 555 timer and negative probe connected to the ground. The capacitor voltage waveform in the form of Ramp wave was observed on the CRO when the positive probe from channel 2 was connected at pin number 6 of the 555 timer and negative probe connected to the ground. The CRO was kept in channel 2 mode. A CRO possess 2 channels namely channel 1 and channel 2, of these two channels any one can be used for seeing the output waveform. The output waveform and the capacitor voltage waveform are depicted in fig. 8 and 9 respectively.

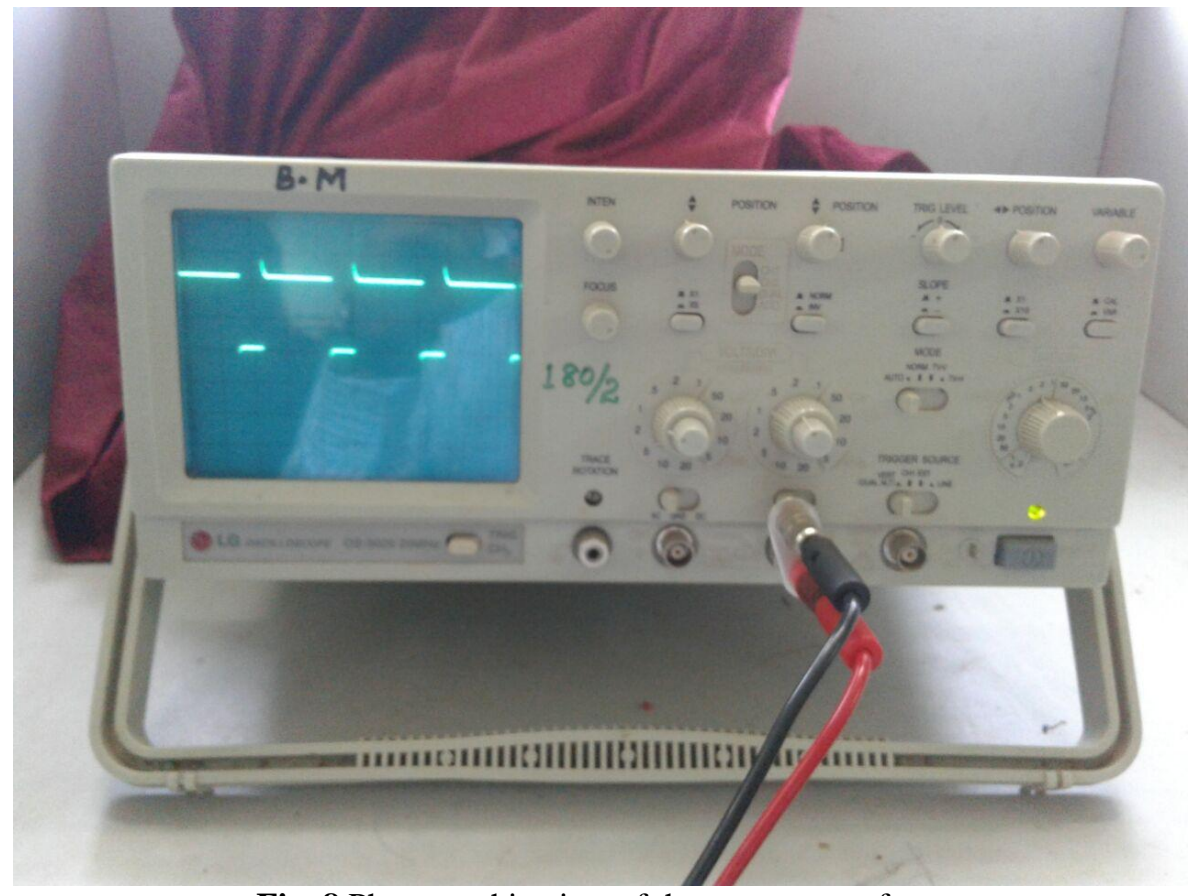

Fig. 8 Photographic view of the output waveform

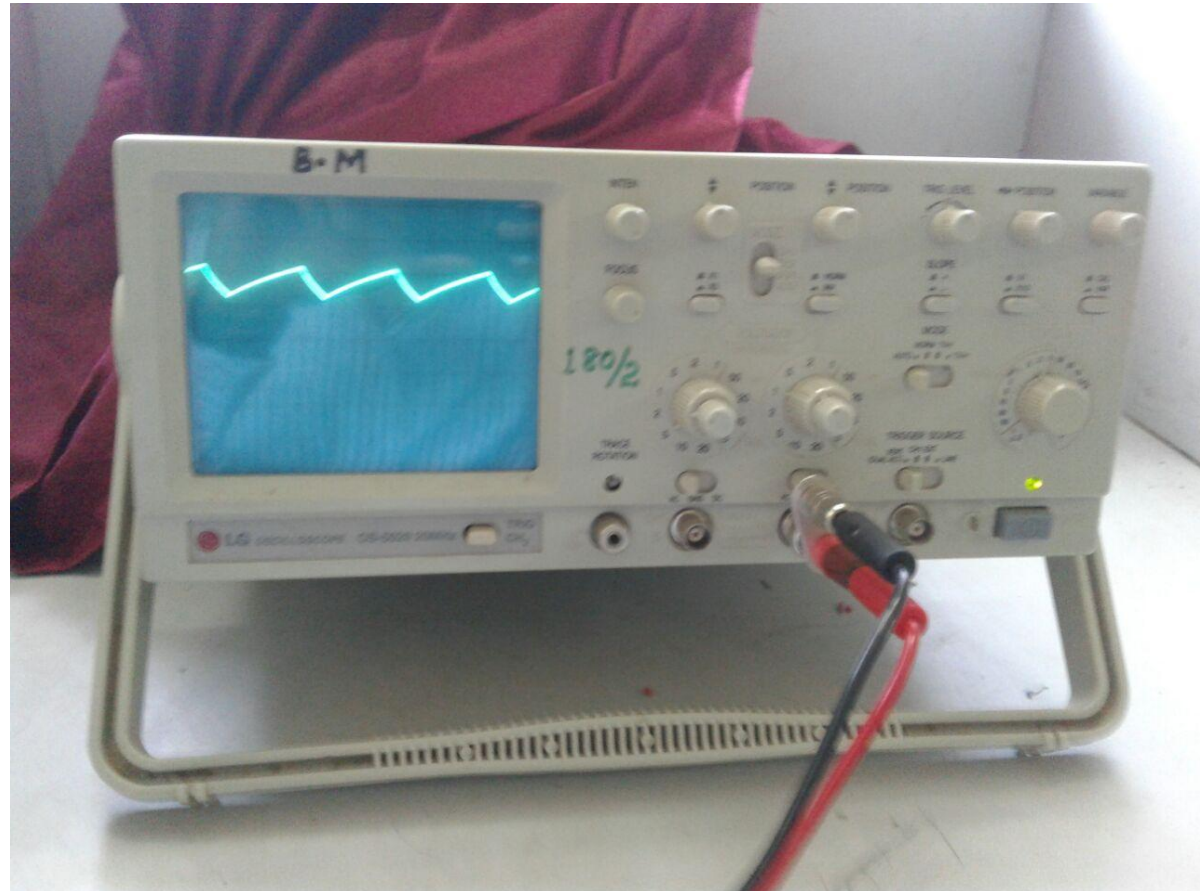

Fig. 9 Photographic view of the Capacitor voltage waveform. 
The amplitude level, of the output waveform was noted down. The total time period (T) was also calculated. It is given by the sum of Turn ON time $\left(\mathrm{T}_{\mathrm{ON}}\right)$ and Turn OFF time $\left(\mathrm{T}_{\mathrm{OFF}}\right)$. After calculating the total time period $(\mathrm{T})$, the frequency $(\mathrm{F})$ of the output waveform was determined. Finally the Duty cycle (D) was calculated.

Amplitude $=($ No of boxes covered by the wave along Y-axis) X (Multiplying factor of channel 2)

$$
\begin{aligned}
& =2.2 \times 1 \\
& =2.2 \mathrm{~V} .
\end{aligned}
$$

Turn ON time $\mathrm{T}_{\mathrm{ON}}=($ No of boxes covered by the wave along $\mathrm{X}$-axis $) \mathrm{X}$ (Time/Division $)$

$$
\begin{aligned}
& =2.2 \times 0.2 \mathrm{~m} \mathrm{sec} \\
& =0.44 \mathrm{~m} \mathrm{sec}
\end{aligned}
$$

Turn OFF time $\mathrm{T}_{\mathrm{OFF}}=($ No of boxes covered by the wave along $\mathrm{X}$-axis $) \mathrm{X}$ (Time/Division $)$

$$
\begin{aligned}
& =0.8 \times 0.2 \mathrm{~m} \mathrm{sec} \\
& =0.16 \mathrm{~m} \mathrm{sec}
\end{aligned}
$$

Total Time Period $=$ Turn ON time + Turn OFF time

$$
\begin{aligned}
\mathrm{T} & =\mathrm{T}_{\mathrm{ON}}+\mathrm{T}_{\mathrm{OFF}} \\
= & 0.44 \mathrm{~m} \mathrm{sec}+0.16 \mathrm{~m} \mathrm{sec} \\
& =0.6 \mathrm{~m} \mathrm{sec}
\end{aligned}
$$

Frequency $\mathrm{F}=1 / \mathrm{T}$

$$
\begin{aligned}
& =1 /\left(0.6 \times 10^{-3}\right) \\
& =1.6 \mathrm{KHz}
\end{aligned}
$$

$\%$ Duty cycle $=[$ Turn ON time/ (Turn ON time + Turn OFF time $)] \times 100$

$$
\begin{aligned}
\% \mathrm{D} & =\left[\mathrm{T}_{\mathrm{ON}} /\left(\mathrm{T}_{\mathrm{ON}}+\mathrm{T}_{\mathrm{OFF}}\right)\right] \times 100 \\
& =[0.44 \mathrm{~ms} /(0.44 \mathrm{~ms}+0.16 \mathrm{~ms})] \times 100 \\
& =73.3 \%
\end{aligned}
$$

TABLE 2. Comparision between Practical values and theoretical values (from design).

\begin{tabular}{|l|c|c|c|c|c|}
\hline \multicolumn{1}{|c|}{ Quantity measured } & $\begin{array}{c}\text { Turn ON time } \\
\mathrm{T}_{\mathrm{ON}}\end{array}$ & $\begin{array}{c}\text { Turn OFF time } \\
\mathrm{T}_{\mathrm{OFF}}\end{array}$ & $\begin{array}{c}\text { Total Time period } \\
\mathrm{T}\end{array}$ & Frequency F & Duty cycle C \\
\hline Theoretical Value & $0.6 \mathrm{~ms}$ & $0.4 \mathrm{~ms}$ & $1 \mathrm{~ms}$ & $1 \mathrm{KHz}$ & $75 \%$ \\
\hline Practical value & $0.44 \mathrm{~ms}$ & $0.16 \mathrm{~ms}$ & $0.6 \mathrm{~ms}$ & $1.6 \mathrm{KHz}$ & $73.3 \%$ \\
\hline
\end{tabular}

\subsection{Simulation Results}

The Astable multivibrator using 555 timer is designed and implemented using Multisim Simulation package. The Simulation circuit and the output waveforms for the simulation circuit are shown in fig.10 and 11 respectively.

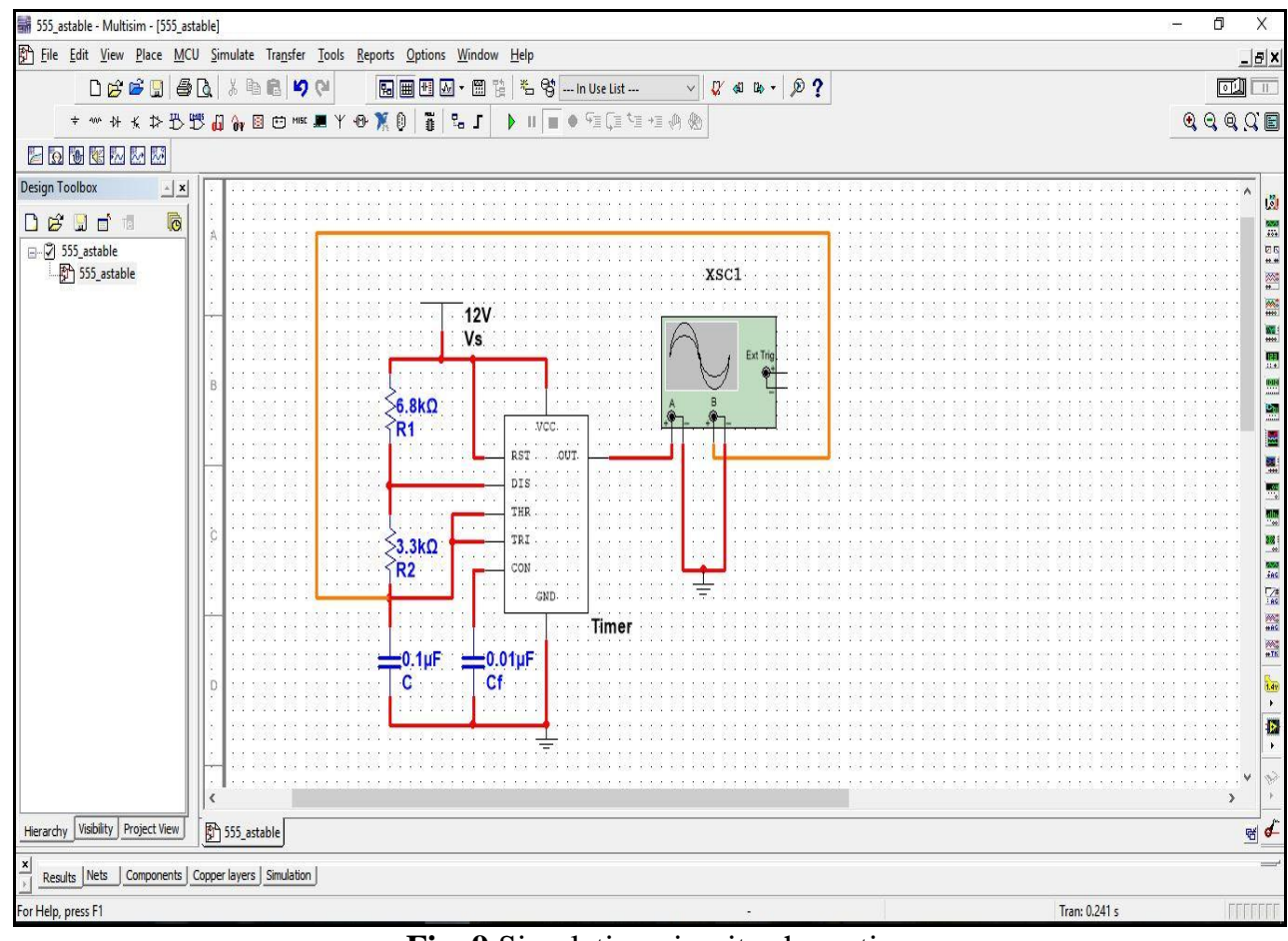

Fig. 9 Simulation circuit schematic 


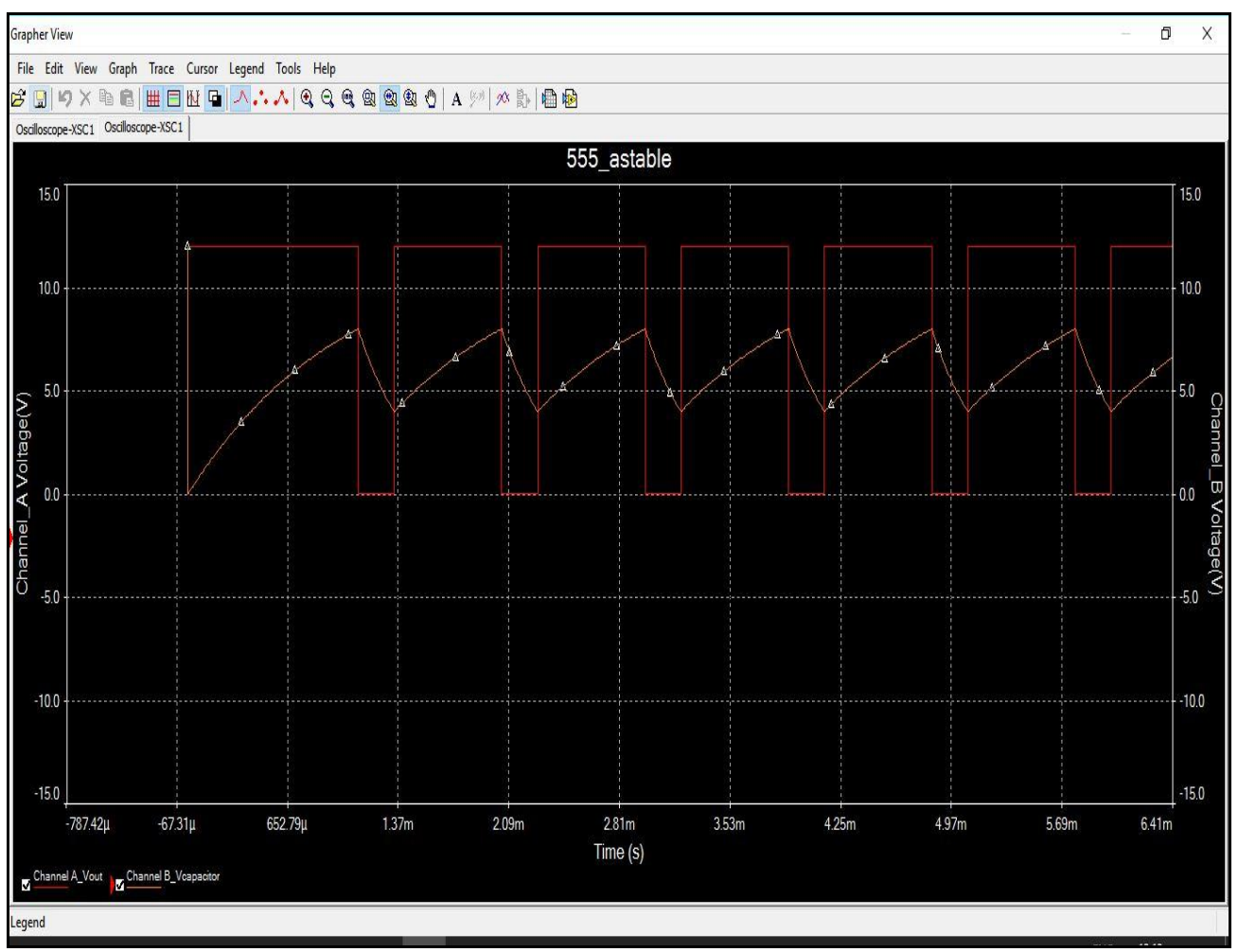

Fig. 10 Simulation circuit waveforms

\section{Conclusion}

Astable multivibrator using 555 timer was designed and implemented. Precise results were obtained through the designed system in the form of continuous production of Rectangular waveform without the aid of any external triggering. From the Rectangular output waveform the Turn ON time, Turn OFF time, the Total time period, the frequency and Duty cycle were calculated. Astable multivibrator circuit is very simple and easy to design requiring few components. As the 555 timer is used the system has low power consumption. The 555 timer will work with any supply voltage between $+5 \mathrm{~V}$ to $+18 \mathrm{~V}$. Furthermore, with the use of 555 timer, the system is very stable, easy to use and requires low cost. In addition another important boon is that, the system can be used for timing from microseconds to hours. Generating time delays from microseconds to hours is useful in many applications. Due to the use of 555 timer it has various advantages and hence it is used in a wide range of applications such as Voltage controlled Oscillator (VCO), Start and Reset operations, Sirens and Alarms, Pulse width modulator, Pulse position modulation, Ramp generation, Music synthesizers, cell phones, pagers and G.P.S wireless transmitters and receivers.

\section{Acknowledgements}

First of all I would like to thank Almighty Allah by the grace of whom I reached the stage of completion of this work. This avenue has been a turning point in my career to mold me into a thorough professional. My sincere thanks to the Principal Dr. S Kamal Md. Azam, Vice Principal Dr. Ruksar Fatima and Dr. Asma Parveen H.O.D CSE Department of my esteemed institution Khaja Banda Nawaz College of Engineering. I am also thankful to my beloved parents who have helped me pave this path to success.

\section{References}

[1] Anil K. Maini, Varsha Agarwal, Electronic Devices and Circuits (New Delhi: Wiley India Pvt. Ltd. 2009), 457-458 and 527-539.

[2] Albert Malvino, David J. Bates, Electronic Principles (New Delhi:Tata Mc Graw Hill, Special Indian edition, 2007), 912-926.

[3] Donald P. Leach, Alberto Paul Malvino, Gautam Saha, Digital Principles and Applications (New Delhi: Tata Mc Graw Hill, Special Indian edition, 2011), 253-255.

[4] A.P. Godse, U.A. Godse, Analog \& Digital Electronics, (Pune: Technical Publications, First edition August 2016), chapter 3, 72-76.

[5] Jain R.P, Anand M.M.S, Digital electronics Practice using Integrated circuits (Tata Mc Graw Hill Education, 1983), 158-160.

[6] Rao Prakash, Pulse and Digital Circuits, (Tata Mc Graw Hill Education, 2006), 267-268.

[7] Timer I.C 555 Data sheet, Philips Semiconductors Linear Products, $31^{\text {st }}$ August 1994, 346-348.

[8] Albert Lozano, Introduction to Electronic Integrated circuits, (Electrical systems Laboratory experiments) 2-4.

[9] Multivibrator in IEEE std. 100 Dictionary of Standard terms (New York $7^{\text {th }}$ edition IEEE press, 2000) 718-720

[10] Donald Fink, Alexander Anderson Mc Kenzie, Electronics Engineers Handbook (Mc Graw Hill, 1975), 16-40.

[11] Scherz, Paul, Practical Electronics for Inventors (Mc Graw Hill/TAB Electronics, 2010), 589-590.

[12] Tony R. Kuphaldt, Lessons in Electric circuit, volume 6, chapter 8, 555 timer circuits. 